\title{
Diplomacia cultural y circulación literaria: dos escritores brasileños en Buenos Aires entre los centenarios*
}

\section{Cultural Diplomacy and Literary Circulation: Two Brazilian Writers in Buenos Aires amongst the Centenarians}

\section{Resumen}

El artículo analiza las visitas de los escritores Paulo Barreto (1915) y Julia Lopes de Almeida (1922) a Argentina, en el contexto de la diplomacia cultural informal desarrollada por los diarios de Buenos Aires y de Río de Janeiro, procurando establecer el impacto que pueden haber tenido en la circulación de la literatura brasileña en publicaciones periódicas argentinas. Se destaca la retórica de la gran prensa comercial y de los mencionados escritores sobre el periodismo y los viajes y se discute el papel que el mercado de lectores de Buenos Aires desempeñó en la formación del campo literario en Brasil.

Palabras claves

literatura brasileña, diarios, revistas, sociabilidad intelectual

\begin{abstract}
This paper analyses the travels of two writers, Paulo Barreto (1915) and Julia Lopes de Almeida (1922), to Argentina in the context of the cultural diplomacy developed by Buenos Aires and Rio de Janeiro newspapers, trying to understand the possible impact they had in the penetration of Brazilian literature in Argentine reviews and magazines. The article focuses the

* Agradezco los valiosos comentarios de los evaluadores anónimos los cuales, sin embargo, no son responsables de los errores que persisten en el artículo.
\end{abstract}


CATEDRAL TOMADA: Revista de crítica literaria latinoamericana / Journal of Latin American Literary Criticism Diplomacia cultural y circulación literaria: dos escritores brasileños en Buenos Aires entre los centenarios

press and these writers rhetoric about journalism, and their travels, and discusses the role played by Buenos Aires market for readers to the formation of the Brazilian literary field.

Keywords Brazilian literature, newspapers, magazines, intellectual sociability

En la historia intelectual y literaria de Brasil, el final del siglo XIX tiene por lo menos una característica que lo diferencia con respecto al período anterior, que imprecisamente llamaríamos romántico: la profesionalización del escritor. Si no se puede hablar de la existencia de un campo literario profesional, se verifican sustanciales transformaciones que van del nivel institucional al discursivo. El surgimiento de diarios, con secciones amplias y variadas, y - a partir de 1900 - de magazines ilustrados; conforma una prensa comercial de amplio tiraje, la cual demanda una especialización de las funciones que abre nuevas oportunidades para la publicación de cuentos, crónicas, poesías, ensayos, crítica literaria y novelas en serie (folletines), lo que permite la consolidación, al menos como identificación y como ideal de "literato" que solamente algunos alcanzarán. Este tipo de escritor, si bien no era nuevo, pasa a tener más oportunidades de dedicarse a la poesía, a la ficción, a la crítica literaria o a la crónica (cultural, o de costumbres, o sobre la vida cotidiana, sin, en todo caso, menciones a la política), a medida que diarios y magazines demandan sus contribuciones en un volumen que sobrepasa la capacidad del reducido número de narradores y poetas característico del siglo XIX, los cuales casi siempre eran también redactores o directores de diarios que servían a grupos políticos específicos, profesores, diplomáticos, juristas, empleados públicos - entre las funciones más comunes.

La fragilidad del mercado editorial o, dicho de otro modo, la imposibilidad del literato de vivir solamente de los ingresos obtenidos con la venta de libros incrementa el papel de la prensa. Es sintomático que en ese período aparezcan las primeras novelas que tematizan el universo literario-periodístico - como los Recuerdos del escribiente Isaías Caminha de Lima Barreto - y, en las décadas subsecuentes, las primeras memorias de escritores en las cuales se aborda la 
bohemia o el ingreso en la carrera literaria por medio de la gran prensa comercial (Rodrigues, “A geração” 237-239).

Al constituirse como fuente de ingresos y mecanismo de consagración, la prensa influye en la posición que cada uno ocupará en el campo literario, en los códigos de conducta (en el marco de una subcultura particular), e incluso en los espacios urbanos en los cuales se puede y se debe transitar. Paradójicamente, acaba por imponer límites a esa profesionalización que no serán sobrepasados en el período aludido. Como consecuencia, el periodista-escritor probablemente será la figura más característica de aquellos tiempos.

En el presente artículo se analizan las visitas de Paulo Barreto y Julia Lopes de Almeida a Buenos Aires, en 1915 y 1922 respectivamente, y se propone una “instancia de consagración” (Bourdieu, "O mercado de bens simbólicos” 100) poco estudiada en lo que se refiere a la historia de la literatura brasileña del período anterior a 1930: la circulación intelectual internacional. Se parte de la noción de "campo" de cariz sociológico, que estudia las practicas de los productores culturales, y se incorpora el análisis de objetos escritos literarios y periodísticos a partir de la perspectiva tanto de la historia cultural, que entiende la literatura como un producto fundamentalmente histórico dependiente de determinadas condiciones materiales de producción y circulación (Chartier, Textos, impressos, leituras), como de la historia intelectual, en su interés por las sociabilidades y la formación de "redes culturales" (Sirinelli).

Los dos escritores mencionados estuvieron en Buenos Aires en el contexto de la conmemoración de los centenarios de las independencias (1910 y 1916 en Argentina; 1922 en Brasil), momento en el que se incrementó el estímulo al intercambio de corresponsales especiales por parte de los diarios, y se verificó la difusión tanto de la sociabilidad intelectual bilateral como de la literatura brasileña en la Argentina. Se puede, a partir de los casos de los dos autores mencionados, establecer nuevos aportes a la relación entre periodismo, literatura, diplomacia, circulación cultural entre los dos países y el proceso de profesionalización de la literatura en Brasil, incluso en su dimensión de género. De tal manera que se puede 
afirmar que el establecimiento de la red intelectual entre Argentina y Brasil es anterior a mediados de la década de 20, época priorizada por los estudios sobre el tema, y que vinculan esa red a las vanguardias. Como se verá, en la difusión de escritores brasileños en Argentina se encuentran muchos autores no identificados como pertenecientes al "modernismo" (en algunos casos, incluso considerados como oponentes estéticos de tal movimiento).

\section{Diplomacia cultural informal y periodismo}

En el contexto de reaproximación diplomática entre Argentina y Brasil, después de la resolución de la disputa fronteriza en la región del río Paraná (la llamada "Cuestión de Misiones") finalizada en 1895, los grandes diarios y magazines de Buenos Aires y Río de Janeiro se dedicaron a fomentar la aproximación, de manera independiente, aunque apelando a veces a los buenos oficios de sus respectivos gobiernos. Decenas de periodistas argentinos visitaron Brasil y otros tantos brasileños la Argentina, en viajes que los diarios trataron con la misma importancia que otorgaban a las visitas de representantes oficiales. No solo se escribían detallados artículos sobre ellos, sino que también recibían agasajos dignos de diplomáticos, como recepción en el puerto, paseos organizados por sitios turísticos, visitas a autoridades, cenas en caros restaurantes, brindis en los salones de las sociedades de periodistas, e invitaciones a espectáculos en los mejores teatros.

Sin embargo, la posición de los visitantes dentro de los círculos intelectuales de su propio país era variable. Mientras los viajeros argentinos más destacados del período 1900-1920 eran dirigentes de la prensa porteña (los hermanos Mitre, Manuel Láinez, Ignacio Orzali y Nicolás Olivari, entre otros), los brasileños de mayor prestigio se identificaban más con la literatura que con el periodismo (Olavo Bilac, Paulo Barreto y Julia Lopes de Almeida). No se trata de afirmar que esos escritores brasileños tenían menos contacto con el periodismo que con la literatura, 
sino más bien que, a diferencia de los escritores argentinos mencionados, no se definían a sí mismos exclusivamente como periodistas profesionales. Procuraban establecerse como escritores que vivían de escribir también para diarios y revistas principalmente, en forma de crónica.

Tal diferencia de procedencia profesional no alteró la dinámica más general de la diplomacia cultural informal (Rodrigues, "Embaixadas originais") que, al fin y al cabo, tenía como principal promotora a la prensa comercial de las dos capitales, la cual también incluía otros intelectuales, tales como diplomáticos-ensayistas (Manuel de Oliveira Lima y Martín García Mérou). Además, la misma nos revela las tensiones inherentes a la profesionalización de la literatura en Brasil, en lo que respecta a dos temas no necesariamente correlacionados: la dificultad de mantener la autonomía frente a la gran prensa comercial, y el papel del género ("sexo") de los escritores. En ese sentido, son particularmente interesantes dos escritores brasileños que estuvieron en Argentina entre los tres centenarios de las independencias: Paulo Barreto (1881-1921) y Julia Lopes de Almeida (1862-1934).

Barreto escribía bajo el pseudónimo de João do Rio y permaneció en Buenos Aires entre el 17 y el 20 de mayo de 1915. El motivo declarado de su viaje fue acompañar el estreno en Montevideo de su obra teatral más conocida, La bella Mme. Vargas. A pesar de que su llegada coincidió con la firma del denominado "Pacto ABC", el 15 de mayo, por los cancilleres de Argentina, Brasil y Chile, como consecuencia de su actuación conjunta el año precedente en la conferencia de Niagara Falls, y del acercamiento promovido por los presidentes Roque Sáenz Peña y Hermes da Fonseca, a partir de 1912, el literato brasileño no fue menos notado por la prensa porteña.

Aunque relativamente joven, Barreto era bastante popular, sus libros fueron bien aceptados por la crítica y tenía acceso a los círculos literarios. Desde 1910 era miembro de la prestigiosa Academia Brasileña de Letras. Había empezado su carrera al convertirse, en 1903, en uno de los principales cronistas del diario más importante de Río de Janeiro, Gazeta de Notícias, en el cual permaneció hasta 1913. A pesar de ser novelista, cuentista y autor teatral, con inclinación a la 
experimentación formal, sus temas ficcionales trataban sobre la vida mundana de la élite carioca con una mirada irónica, pero también demostrando cierta adhesión a los valores mundanos, lo que, junto a su estilo peculiar de vestirse, le granjeó la fama de dandi. Con todo, el reconocimiento del público fue consecuencia de incursiones y reportajes que realizó entre las camadas populares y entre los literatos de Río de Janeiro: El alma encantadora de las calles, Las religiones de Río y El momento literario.

En el primero, siguió el modelo parisino del flâneur, haciendo comentarios en forma de crónicas a partir de un recorrido por la ciudad que tematizaba la miseria, el abandono y lo insólito, procurando mostrar sujetos inadaptados y espacios abandonados por la modernidad de la capital que, por aquel entonces pasaba por reformas que buscaban aproximarla del modelo de urbe parisina, con una mirada que para Julia O’Donnell revelaba un "temperamento etnográfico". En el segundo libro, adoptó los modelos del periodismo investigativo norteamericano y de las obras francesas que describen los individuos y lugares marginales y marginados de las grandes ciudades. Tanto El alma encantadora como Las religiones reunían textos publicados con anterioridad en la Gazeta y en el magazine Kosmos. Su aproximación a ese universo popular se aparta mucho de la retórica más militante, indignada y emotiva de las denuncias de otro joven cronista - Afonso Henriques de Lima Barreto (Pesavento, O imaginário da cidade 199-200), quien, en Recuerdos del escribiente Isaías Caminha, retrata a Barreto como un oportunista. Para Juliana Farias, su fascinación por los despreciados y su originalidad al inaugurar la crónica-reportaje no ocultan su prejuicio, sobre todo sus comentarios racistas dirigidos a los afro-brasileños.

En el tercer libro utilizó la técnica del “interview” desarrollada por el reportero de Le Figaro, Jules Huret, en Enquête sur l'évolution littéraire (1891). Sus entrevistados eran 35 escritores, críticos literarios y filólogos brasileños, a quienes hizo preguntas sobre sus carreras, sus influencias, sus técnicas de trabajo, sus impresiones sobre los rumbos de la literatura brasileña y su relación con el 
periodismo. Entre los entrevistados estaba Julia Lopes de Almeida, a la cual nos referiremos en el próximo apartado.

Desde el punto de vista de la diplomacia cultural informal desarrollada por los diarios, Barreto y Almeida presentaban a la vez tres ventajas. Primero, estaban entre lo mejor de la literatura brasileña de su época, por lo que podían ser considerados representantes de la "cultura nacional". Segundo, una temática urbana sin exotismos, referente a un estilo de vida que imitaba las modas de París, también permitía un diálogo con los representantes de las "clases altas", o de la "sociedad" porteña, e ilustraba sin necesidad de otros elementos, el grado de civilización alcanzado por Brasil - civilización que, como se sabe, tenía como modelo a la burguesía europea, sobre todo la parisina. Finalmente, su alejamiento de la crónica política los ponía a salvo de las cuestiones diplomáticas, evitando que pudieran ser identificados con posiciones nacionalistas y, por ende, anti-argentinas. ${ }^{1}$

Se pueden verificar claramente esas ventajas en la forma en que se recibió a esos dos escritores brasileños en Buenos Aires y en el lenguaje con el que en las noticias se describe dicha acogida. A pesar de su corto pasaje por Buenos Aires, Paulo Barreto fue recibido con honores por el Ministro brasileño Luiz Martins de Souza Dantas en una cena en la que estaban presentes, además de diplomáticos de otros países, altos representantes de la prensa porteña. El lugar elegido para el evento (salón del Jockey Club) y la presencia del ministro de Relaciones Exteriores (José Luis Muratore) y de los directores de los diarios más importantes de la capital subrayan la relevancia de la celebración: Jorge Mitre (La Nación), Manuel Láinez (El Diario), Mariano de Vedia (La Tribuna), José A. Cortejarena (La Razón), Natalio Botana (Crítica) y Francisco Juan Uriburu Uriburu (La Mañana). Asimismo, participaron otros importantes periodistas, como Ignacio Orzali y Alberto Gerchunoff, secretario uno y redactor el otro de La Nación. Se hizo notoria

\footnotetext{
${ }^{1}$ A pesar de que a partir de 1915 los dos países se vincularan - junto a Chile - al llamado "Pacto $\mathrm{ABC}$ ", por el cual pretendían crear un polo de resolución de conflictos en América Latina que contrarrestara el poder de Estados Unidos, la historia de innúmeros atritos militares y diplomáticos, desde el siglo XIX, hacía que la prensa de Argentina y Brasil continuara a comentar la existencia de una rivalidad casi natural entre dichos países.
} 
la ausencia de representantes de La Prensa, el diario de mayor circulación en Argentina. La razón más probable es que La Prensa había liderado, entre 1906 y 1912, una campaña de fuertes críticas a la diplomacia y a la política armamentista brasileña y se convirtió en "enemiga de Brasil" según varios diarios cariocas.

Las cenas en lugares elegantes, con la presencia de representantes de la prensa, del gobierno y de la "sociedad", con brindis y discursos, claramente seguían un modelo de sociabilidad burguesa importada de Londres y París. Su homología con las cenas diplomáticas era evidente, y reforzaba la conceptualización de los escritores y de los periodistas como representantes destacados de sus países. Los principales diarios de Buenos Aires tratan a Paulo Barreto como "huésped" ("El Sr. Pablo Barreto" 4; "Pablo Barreto - su llegada" 1; "Pablo Barreto" 1; "En honor de Barreto" 1; "Vida social" 8). También es significativa la categoría adjudicada a Julia Lopes de Almeida por la prensa de Rio: "embajadora de las letras brasileñas" ("Embarcou para esta capital, a escritora patrícia D. Julia Lopes de Almeida" 9)2, en cumplimento de una "misión intelectual" ("O Brasil no estrangeiro", 1). ${ }^{3} \mathrm{El}$ sentido más amplio de esas ocasiones, en el contexto en que Argentina y Brasil intentaban implementar un proyecto de hegemonía compartida con Chile en el equilibrio diplomático del continente, fue bien expresado por el diario Tribuna, de Buenos Aires, al caracterizar la cena en honor a Barreto, como una "fiesta de verdadera confraternidad sudamericana" ("En honor de Barreto" 1).

Es interesante notar que Barreto había intentado ingresar en el cuerpo diplomático a principios de la década de 1900. Circulaba en los medios intelectuales y fue rechazado por ser mulato y homosexual. Sin embargo, su exclusión no le impidió ser recibido como un "brillante representante de la inteligencia de Brasil" ("Pablo Barreto", 1), clasificación que no lo limitaba a la categoría de escritor, sino que también indicaba su función de mediador entre la cultura argentina y la brasileña. Además de los elementos destacados hasta aquí, se puede notar la

${ }^{2}$ En portugués en el original. Todas las traducciones, salvo indicación, son de mi autoría.

${ }^{3}$ En los diarios porteños Almeida recibe el mismo tratamiento que Barreto: "huésped" ("Vida intelectual" 4; "Círculo de la Prensa: ayer se efectuó una recepción" 2). Su viaje también fue entendido como "misión intelectual" por parte de Crítica ("La alta oratoria de anoche" 1). 
importancia simbólica de esa función en el hecho de que Barreto, aunque en el marco de una visita tan breve, merece figurar con su fotografía en la portada de $E l$ Diario del 18 de abril.

En el epígrafe de dicha fotografía se indica cómo João do Rio, a diferencia de Julia Lopes de Almeida, se presentaba en una posición menos circunscripta a la literatura; El Diario lo definió como "literato, periodista, crítico y autor dramático". Tal vez porque percibía la importancia de la prensa en la vida cultural y pública de Argentina y sin poder evaluar el grado de conocimiento de los argentinos sobre la literatura brasileña, ${ }^{4}$ el cual sería difícil de sobrepasar en su breve viaje, Barreto concentró sus intervenciones (el discurso y una crónica en El Diario) en el tema del periodismo.

En el discurso que pronunció en la cena en su honor, se presentó como “americano y periodista entre americanos y periodistas". Exaltó la profesión de los presentes: "los gobiernos son transitorios, las administraciones recelosas, el arte una fantasía poco considerada. Solamente está en pié, firme, definitivo, cada vez mayor y más formidable el Periodismo Rey, el periodismo pastor de los hombres, el periodismo supremo, el periodismo tirano" ("En honor de Pablo Barreto" 2; "En honor del Sr. Barreto - la comida de anoche" 2). ${ }^{5}$

Aunque algunas de las imágenes que evocaba en su discurso (como la tiranía) no fuesen exactamente elogiosas, definía claramente el periodismo como la profesión más importante de aquellos tiempos, ya que debido al poder de lo impreso y la formación de la opinión pública, terminaba siendo el responsable del movimiento histórico. En aquel 1915, Barreto entendía que tanto Argentina como Brasil estaban marcados por el progreso, por el trabajo intenso y la adopción de "la vida moderna", agitada e inconstante ("En honor de Pablo Barreto" 2). De tal

${ }^{4}$ Era común el tema del desconocimiento mutuo de la cultura entre los dos países. Entre varias expresiones se puede destacar su mención por José Veríssimo en una crónica de 1899 (Homens e coisas estrangeiras 71-77) y García Mérou en sus artículos para La Biblioteca en 1897 (El Brasil intelectual 1-3).

${ }^{5}$ En español en el original. Un resumen del discurso fue noticiado en: "En honor de Barreto - el banquete de anoche", La Tribuna, 20/04/1915, p.1. Posteriormente estaría accesible al público brasileño (Barreto, Sésamo 61-66). 
manera que, en su discurso de brindis, la literatura pasaba a un segundo plano: "Y en la vida contemporánea, en la vida americana, solo hay una fuerza sin desfallecimientos y un arte creador: el diario" ("En honor de Pablo Barreto" 2).

Sin embargo, João do Rio no compartía una opinión totalmente positiva respecto del periodismo, pues afirmar su importancia en la modernización de Sudamérica no significaba por ende que se trataba de un proceso sin pérdidas. Que fuera inevitable no implicaba que fuera unívoco. Dos días después de la cena en su honor, El Diario publicó un cuento de Barreto bastante significativo. Aunque fuera una ficción, su tema seguía siendo el periodismo: se trata de la historia de un joven que al llegar a la capital y busca empleo como reportero en una redacción. Los cronistas y redactores lo llevan a cenar y argumentan que, aunque la vida en el periodismo arrebatara todos los ideales de la juventud a cambio de un salario miserable, el prestigio que se alcanzaba si se manejaban bien las armas frente a políticos y empresarios (amenazando escribir noticias negativas o prometiendo redactar noticias positivas) permitía, en la madurez, vivir de una renta indirecta bastante compensadora: comidas en los restaurants chics, acceso a clubes de élite, entradas gratis a teatros, cuartos en los mejores hoteles. Esta vida lo fascina y después de algunos años asciende al cargo de redactor. Otro joven llega de la provincia, y el cuento termina volviendo sobre la situación inicial: en un diálogo entre el periodista veterano y el principiante que pide empleo en el diario ("Esplendor y miseria del periodismo" 4). Dicho cuento se publicó originalmente en 1911 en la colección Vida vertiginosa (171-180). Varios cuentos de esta obra abordan la cuestión de cómo la modernidad hace desaparecer tanto los parámetros de juicio individual como la sensación de seguridad en relación con personas e instituciones cotidianas, pero sin presentar esos cambios como angustiantes o indignos, sino más bien como hechos de la vida (a veces con intenciones cómicas) a los cuales uno se adapta o perece. Sin embargo, la lucha por la vida no se presenta como verdaderamente mortal o destructiva. En todo caso, es inequívoco que el cuento presenta a la prensa como una institución bastante poderosa. 
La elección de "Esplendor y miseria del periodismo" para que constara como traducción en las páginas de El Diario indica que su editor lo entendió como cercano a la experiencia porteña y, por lo tanto, descifrable por sus lectores (no se indica en el cuento de qué provincia provenía el joven, apenas que llegó “del norte" y ni siquiera se informa la ciudad en donde se desarrolla su carrera). Parece haber una confluencia entre el diario porteño y el cronista carioca en cuanto al vínculo entre periodismo y literatura. Además, esa relación se pone en evidencia en el hecho de que Paulo Barreto llegaba a Buenos Aires distribuyendo sus libros entre sus colegas de la prensa ("En honor de João do Rio" 1) y además en la descripción que El Diario hacía del escritor: "literato, periodista, crítico y autor dramático" ("El Sr. Pablo Barreto [Joao do Rio]” 1). Fue de esa manera que un escritor carioca destacó el tema del periodismo como un vector preponderante de la modernidad, en al menos tres frentes: en su sociabilidad intelectual, en el discurso en un evento “diplomático" y en la publicación de una pieza ficcional.

Sin embargo, dicho vector no aparecería tan claramente cuando volvió a Río - al menos si tomamos el testimonio del autor. En las diez crónicas sobre su viaje que Barreto publicó en la Gazeta de Notícias (del 27 de abril al 6 de mayo), los tres temas más destacados son la sociabilidad de los viajes en transatlánticos, la arquitectura y el trazado urbano de Buenos Aires, y la prensa argentina - la cual merece una crónica especial. Su opinión es tajante: “el periodismo argentino es el primero de Sudamérica y uno de los más perfectos que conozco”. Los argumentos que utiliza son un poco vagos y los ejemplos escasos. En comparación con los diarios de Río de Janeiro, sigue el autor, su superioridad se basa en tres elementos: ejercen influencia sobre todo el país; no tienen columnas "libres" (espacio que se alquila a cualquier persona fuera del cuerpo de periodistas del diario); son patriotas, pues no menoscaban a la nación en comparación con otros países. Barreto no fue económico en los elogios: "para mostrar su agudísima civilización la Argentina no necesitaría más que mostrar sus diarios" (Barreto, "A imprensa" 2). La valoración del periodismo argentino sobre el brasileño era una consecuencia de la política de aproximación, en un momento en que la noción de "progreso" aún era bastante 
fuerte y la opinión sobre la capacidad argentina de alcanzarlo se encontraba bastante difundida entre los literatos de Brasil (Rodrigues, "Da revolução"). Además, reforzaba los lazos entre las dos naciones al demostrar que la diplomacia cultural informal les rendía prestigio. Se establecía un sistema de beneficios mutuos, dado que Barreto podía presentarse en Río como un invitado de honor de uno de los periodismos más destacados del mundo.

En esas crónicas tampoco se mencionaba la literatura argentina, dejando al lector la posibilidad de especular sobre si el periodismo porteño, tal como el carioca, difundía piezas literarias. Sin embargo, como se verá en el último apartado, tal silencio sobre la literatura no quería decir que esta estuviera ausente en su viaje. En los años siguientes parece haber surgido un tímido mercado para sus textos, pues algunos de sus cuentos y crónicas fueron publicadas en revistas porteñas.

Algo semejante parece haber ocurrido con Julia Lopes Almeida, aunque ella no tuviera vínculos tan estrechos con el periodismo. La escritora que visitó poco después Buenos Aires recibiría agasajos con un sentido un poco diferente.

\section{La literatura en género femenino}

Julia Lopes de Almeida permaneció en Buenos Aires entre el 3 de octubre y el 2 de noviembre de 1922. También se encontraba en la plenitud de su reconocimiento literario. A pesar de formar parte del segundo o tercer diario más importante de Río, O País, sus novelas y colecciones de cuentos también la granjearon reputación como escritora. Su actividad en ese diario se vinculaba tanto con la crónica cuanto con la ficción: sus cuentos se publicaban los domingos. Sus obras ficcionales se dedicaban a tematizar el matrimonio y la vida íntima de las mujeres de élite. En sus primeras novelas de fines de la década de 1880, su abordaje aún presenta trazos románticos. A partir de 1900 su estilo abandona los moralismos, pero sin apelar al escándalo, en un estilo intimista y de contención muy cercano al realismo (Lucca, Feminismo e iluminismo 213-236), y distante tanto del 
naturalismo, de moda en la década de 1890, como de las vanguardias que empezaban a aparecer en la década de 1920. En los círculos intelectuales se decía sin reticencias que la Academia de Letras había elegido a su marido, un escritor mediocre, como una solución en su honor, pues los estatutos, copiados de la Académie Française, no permitían la inclusión de representantes del "beau sexe" (El Far, A encenação 53-54).

Si Paulo Barreto fue tratado casi únicamente como periodista, Almeida lo fue como mujer y escritora. Hubo otra diferencia: las noticias de la Gazeta de Notícias sobre la cena en honor al cronista mencionan solamente presencias masculinas. Los diarios ponen de relieve la presencia de diplomáticos, profesores, periodistas, y mujeres de la "sociedad" en los eventos en honor a Almeida ("Aspectos del desenvolvimiento y la vida actual del Brasil" 4; "Biblioteca del Consejo Nacional de Mujeres" 4; "Vida intelectual” 4; "O Brasil no estrangeiro: missão intelectual ao Prata" 1; "Embarcou para esta capital a escritora patrícia D. Julia L. De Almeida" 9). Las distinciones indican un cambio con relación a la importancia que se le otorgaba a la diplomacia cultural informal, que a partir del final de la Primera Guerra Mundial no será más monopolizada por la gran prensa comercial. En muchos aspectos se puede decir que tal "diplomacia" empieza a decaer, lo que se relaciona con la presencia de escritores, particularmente los argentinos, que viajan por su propia cuenta, como Nicolás Olivari, Lorenzo Stanchina y Enrique González Tuñón (en 1924, 1925 y 1929), o incluso cuando representan un diario, como Roberto Arlt (en 1930).

Las distinciones también indican otro sutil cambio con respecto a la cuestión de género en la literatura: al identificar la presencia femenina en las tertulias de Almeida, tanto la prensa carioca como la porteña vinculaban dicha presencia a un quehacer intelectual, lo que se relaciona con el tema de la profesionalización literaria de la mujer. Si bien la imagen de ese género difundida de manera hegemónica en las revistas seguía siendo la de "la inmovilización en el hogar" (Fernández, Los límites morales 22), relacionada a la maternidad, al cuidado de su belleza y a "modales apacibles" (Diz, Alfonsina periodista 53), a mediados de la 
década de 1910 algunas escritoras empezaron a combatir esos estereotipos, como Alfonsina Storni. Incluso cuando otras autoras, como las que surgieron a partir de la labor del Consejo Nacional de Mujeres y que se tornaron cronistas de la revista Plus Ultra, valoraban el papel de la madre y de la caridad, se notaba un nuevo discurso de defensa del papel público de "bello sexo" como educadora de los hijos e hijas de la nación. En ese caso, se trataba de la valoración tanto de la actividad de las maestras del sistema educativo cuanto de la propia actividad literaria de las escritoras (Ariza, Bellezas argentinas).

Julia Lopes de Almeida fue a Buenos Aires justamente invitada por el Consejo Nacional de Mujeres a dar una conferencia. Su visita no pasó inadvertida, tanto para los diarios porteños como para los cariocas, dado que recibió una invitación para una recepción en el Círculo de la Prensa y al llegar a Río $O$ Imparcial y $O$ País la entrevistaron. El Consejo le hizo llegar la invitación a través de los canales oficiales: se dirigió a la representación diplomática brasileña en Buenos Aires, la cual se comunicó con el Ministerio de Relaciones Exteriores en Río. El motivo expreso era homenajear el centenario de la independencia de Brasil. Dado que el gobierno brasileño preparaba una exposición internacional, reforzó la invitación por medio de cartas de los organizadores de la "Comisión Ejecutiva del Centenario", destacando la importancia del gesto y del viaje de Almeida a Argentina. Según el Ministro de Justicia, Joaquim Ferreira Chaves, de esa manera se inauguraría "el intercambio intelectual femenino entre los dos países" ("Conferência sobre o Brasil em Buenos Aires"). Además de la conferencia del 10 de octubre, recibió una invitación para una soirée musical en su honor el 28, y para obras sociales de caridad relacionadas con el Consejo ese mismo mes.

Las palabras del ministro Chaves y otros detalles del viaje de Almeida ponen en evidencia un elemento que la distingue de los demás viajeros intelectuales brasileños en Argentina: su condición femenina. A diferencia de la casi totalidad de los periodistas o intelectuales brasileños que visitaban Buenos Aires (todos hombres), Almeida no se embarcó, ni hizo paseos sola. La acompañaba su hija Lucia. Un hecho más representativo aún que esta circunstancia familiar, era la 
retórica de la prensa, del Consejo y de la propia escritora. Si bien estaban presentes temas de la diplomacia cultural (cordialidad, hospitalidad, amistad), también se mencionaron condicionantes de género que dieron a la visita un carácter original.

Probablemente el diario que más elocuentemente expresó las expectativas alrededor de la presencia de Almeida en la capital argentina fue $O$ País que publicaba sus crónicas y cuentos, para el cual ella tenía tanto cualidades intelectuales típicas de una gran escritora, como "santas virtudes de esposa y madre", que serían "la propaganda de lo mejor que podemos y debemos mostrar en el extranjero" ("Missão auspiciosa" 3). Todo lo que ligara "las dos naciones, las dos sociedades, las dos familias" era digno, continuaba el redactor. De esa manera, una escritora no solo alcanzaba las esferas a las que normalmente llegaban los intelectuales en sus visitas - el Estado y la sociedad civil - sino también a la familia, porque la viajera era capaz de impulsar, más que los hombres, esas relaciones con el "corazón" y el "alma". A pesar de que desde mediados de la década anterior no existían más contiendas entre Argentina y Brasil, una representante del sexo femenino que reuniera "inteligencia, ternura y afecto" tendría la capacidad de expresar los ideales de confraternidad entre las naciones de una manera más expresiva y auténtica que los varones. Podría plantar una "semilla" que si se la cuidaba daría como resultado "dulzura" y "fraternidad" entre los dos pueblos ("Missão auspiciosa" 3). Si, por un lado, el sentido que se atribuía a la visita apelaba a temas típicamente cristianos, románticos y victorianos sobre al papel de la mujer en la sociedad, por otro, no se ocultaba del lector la ocupación de espacios tradicionalmente masculinos, como la diplomacia.

En consecuencia, su actuar buscaría llegar al público femenino de Buenos Aires, sin excluir el masculino, y vincularía su condición de género a la divulgación de la cultura brasileña. En la conferencia que dio en la biblioteca del Consejo Nacional de Mujeres, ante un público de diplomáticos, de "señoras", y de "muchas personalidades intelectuales y familias conocidas de nuestra sociedad", Almeida dedicaría la parte final de su discurso sobre la historia y la cultura de su país a nombrar, según La Nación, a las "numerosas mujeres que ilustran la cultura" y "a 
la obra que desarrolla la mujer en su país" (“Aspectos del desarrollo y la vida actual del Brasil" 4). Como notan varios autores (Fanini, Júlia Lopes de Almeida 159199), la escritora buscaba, sobre todo a partir de la década de 1910, incentivar la profesionalización literaria femenina, tema que se hace presente en su conferencia ante los porteños - y especialmente ante las porteñas. Se nota, por lo tanto, puntos de contacto entre esa búsqueda de la escritora brasileña y la de una parte de las mujeres relacionadas al Consejo.

A diferencia de la retórica de Paulo Barreto (poco original en ese punto), orientada por el impacto del progreso argentino como expresión de la lucha por la vida, Almeida y los reporteros que la entrevistaron en Brasil se expresaron en términos más intimistas. La escritora destacó a $O$ imparcial que de Buenos Aires recordaba el buen "gusto" de la gente y la omnipresencia de las flores, desde los parques hasta los restaurantes. Del mercado público de la ciudad le había impresionado "la cortesía y educación admirables" de la gente. La imagen que vinculaba estética y sociabilidad aproximaba a Almeida y a la Argentina; ambas parecían compartir las mismas cualidades. El reportero de $O$ Imparcial introducía el diálogo con una descripción de la casa de la escritora que se adecuaba a esos aspectos: "nido refinado del arte, donde todo es belleza", un ambiente "tranquilo" y "de simplicidad" que contrastaba con la urbe agitada que rodeaba la residencia ("Como nos vê o povo argentino" 1).

En otra entrevista, la "ternura" que el reportero identifica como una actitud de Argentina frente a Brasil, se refleja en la escritora, quien se llevó una "palabra de afecto de Brasil". Julia Lopes de Almeida una vez más destaca características personales: el varón argentino es "elegante" y "físicamente hermoso"; la mujer de "la alta sociedad" es "muy amable", simpática, inteligente (pues tiene su biblioteca particular), y en referencia a algunas mujeres, menciona su espíritu caritativo y su amabilidad ("A Argentina contemporânea" 3-4). Entre las palabras de Almeida y la de los diarios había una confluencia en torno al intimismo como perspectiva de apreciación tanto de la posición de la escritora como de la presencia femenina en la cultura porteña, las cuales surgen casi como pares complementarios. 
No obstante, la técnica del "interview" que aún dominaba era el modelo literario, debido a lo cual el periodista se permitía floreos e incluso la creación de preguntas y respuestas que no habían sido efectivamente intercambiadas durante el diálogo entre el reportero y el entrevistado. Así, es posible que la reiteración de los papeles tradicionales de género no fuera obra de Almeida, sino más bien del reportero, del redactor o del editor - o de los tres. En todo caso, se nota la valoración del tópico de la "intimidad" típica, según Alain Corbin, de una estructura de sentimientos burgueses que tan solo concomitantemente a la Primera Guerra Mundial se disolverían.

Es interesante notar que también se constata el tema vinculado a la cuestión de género en el cuento traducido y publicado por La Nación durante la estadía de la autora en Buenos Aires. Se trata de la historia de un joven atormentado por la vergüenza que siente por su madre viuda, y que además es tuerta. Desde chico sus amigos de escuela o sus colegas de empleo, donde intentaba aprender un oficio, lo molestan con apodos despreciativos, normalmente el de "hijo de la tuerta", de tal manera que cuando su novia le exige que vayan a vivir lejos de su madre, el joven acepta, no sin gran culpa, pues la madre siempre, estoicamente, había aceptado la reclusión domiciliaria para no empeorar la vergüenza de su hijo exponiendo públicamente su fisonomía repulsiva. Sin embargo, cuando recibe la noticia, la madre se desespera y maldice al hijo por ingrato; este le pide a su única amiga que intervenga y ella consiente, pero con la condición de revelar la causa por la cual su madre perdió un ojo. La historia termina con la revelación de que la culpa era del hijo pues cuando niño lastimó a su madre con un tenedor (Almeida, "La tuerta" 8). ${ }^{6}$ El cuento no narra la reacción del hijo después de la revelación, pero su desarrollo sigue entre el tono patético del romanticismo y la exploración de los sentimientos de culpa y amargura del realismo.

Por un lado, a pesar de no proponer una clara lección moral, aborda temas tradicionales respecto de la maternidad, de la conducta "respetable" de la mujer y

${ }^{6}$ El cuento fue originalmente publicado en 1903 en una colección de relatos (Almeida, Ansia eterna 93-102). 
de la fidelidad de los hijos. Así que, si bien no hay una redención del "hijo de la tuerta" o una recompensa para ella, se tematiza el conformismo maternal y la importancia del amor en la familia. Consecuentemente, se puede notar una complementariedad entre el perfil de la visita de Julia Lopes de Almeida, acompañada de su hija, (con la visita de escuelas, prisiones, hospitales y asilos de niños expósitos), la retórica de sus entrevistas, fijadas en la dedicación y amabilidad de la mujer argentina, y el ejemplo de literatura de una autora brasileña que se presenta al público porteño a través de La Nación.

Por otro lado, se puede leer el cuento en otra clave, alineada con la mirada de Sandra Gilbert y Susan Gulbar sobre las escritoras mujeres del siglo XIX y su propia imaginación literaria, vinculada a formas sutiles de denuncia de la condición de la mujer y de la inversión de papeles. Si el personaje masculino es claramente inseguro y débil, física y emocionalmente, el triángulo femenino no lo es - muy al contrario. La novia y la amiga son impositivas y la madre es resoluta y estoica. Al mismo tiempo, la narrativa desvela la cotidianeidad de reclusión obsesiva, casi claustrofóbica de la madre, en la cual el universo masculino, en el que se educa su hijo genera violencia en contra sí mismo y ansiedad, culpa y, por ende, desilusión en la madre. Si comparamos este cuento con las ficciones publicadas en revistas de novelas analizadas por Sarlo (El imperio), se perciben grandes diferencias: la presencia del mundo del trabajo doméstico, la mujer pobre que no es bella y la pareja amorosa como un obstáculo para la felicidad familiar.

\section{Los viajeros y la literatura brasileña en Argentina}

¿Y cuál fue la consecuencia de esos dos viajes desde el punto de vista de los interrogantes iniciales: la relación entre la difusión de la literatura brasilera en Argentina y los mecanismos de consagración y profesionalización intelectual en Brasil vinculados a la prensa comercial? Existen fuertes indicios de que el público porteño de la época tuvo más acceso a la producción brasileña de lo que sus 
contemporáneos afirmaban - o como se desprende de algunos estudios actuales, como los de Alcalá y Schwartz, Artundo, Ribeiro y Bravo, que solamente investigan los intercambios literarios entre las vanguardias de las décadas de 1920 a 1940. En el dominio de la traducción, Gustavo Sorá y Pablo Rocca identificaron la presencia de cinco ediciones de novelas brasileñas, entre 1900 y 1920, particularmente en la Biblioteca de La Nación. Sorá afirma que la hegemonía de las relaciones diplomáticas en la conducción del contacto intelectual entre los dos países, hasta los años 1920, sofocó la traducción en pro de la edición de libros o artículos de carácter prospectivo sobre la realidad social y política de Brasil escritos por autores argentinos.

Sin embargo, Sorá no considera las traducciones de otros tipos de ficción más allá de la novela en la variada prensa periódica. Además de los cuentos de Almeida y Barreto, en las páginas de los diarios se encuentran muestras de poetas y prosadores brasileños. Rubén Darío, por ejemplo, publicó en La Nación, en 1909, un artículo sobre Fontoura Xavier, con la traducción de algunos de sus sonetos y versos (Darío 5). Pero las publicaciones que parecen haber contribuido en mayor medida con la difusión de la literatura brasileña en el período de los centenarios fueron las revistas ilustradas de interés general, como Atlántida, Fray Mocho y Plus Ultra, y las publicaciones semanales de narraciones y de dramaturgia, como La Novela Semanal, llamadas por Jorge Rivera (39) de "publicaciones de kioscos”. En sus páginas los lectores encontraban un panorama razonable de cuentos de autores de "escuelas variadas": Machado de Assis, Aluísio Azevedo, Cyro Franklin de Azevedo, Henrique Maximiano Coelho Neto, José Joaquim de Medeiros y Albuquerque, Monteiro Lobato, entre otros. En menor medida, también se divulgaron en sus páginas varios poetas (de Olavo Bilac a Manuel Bandeira).

Quizás sea emblemático de esa breve tendencia de fines de la década de 1910 y durante la década de 1920 el caso de Cyro Azevedo, un diplomático asignado a la legación en Montevideo, que envió especialmente a La Novela Universal un manuscrito inédito (no está claro si en portugués o en español). Escritor de escasa producción literaria, ¿sería un caso probablemente único de un 
autor con una pieza literaria publicada en Argentina antes que en Brasil? ¿O se lo puede comparar con el investigador de la policía de San Pablo, Amando Caiuby? Antes de publicar su primer libro de crónicas sobre sus experiencias policiales, envió el cuento "El tísico" a Buenos Aires (Caiuby, "El tísico"). Es posible que haya sido estimulado directamente por el ejemplo de Monteiro Lobato, pues el referido libro fue publicado por la casa editorial de este autor (Caiuby, Noites de plantão). Algo similar puede haber ocurrido con otro literato, Mario Sette. Ese escritor pernambucano colaboró con la Revista do Brasil, fundada en 1916 por Lobato, la cual dedicaba bastante atención a las letras argentinas, como se mencionará a continuación.

En 1922 su "novela" (en el sentido que tiene en portugués o italiano, de una narrativa entre el cuento y la novela) Rastro de sangre, publicada posteriormente por una editorial portuguesa para el mercado brasileño, fue aceptada por una "publicación de kiosco" (Sette, "Rastro de sangre"; Sette, João Ignacio). Debido a la relación que tenía con Lobato, ¿sabía Sette del relativo éxito de este autor en las revistas de Buenos Aires y decidió imitarlo? Sette no dejó información clara al respecto. Sin embargo, en su autobiografía informa que mantenía contacto directo con intelectuales y escritores argentinos (Manuel Galvéz, Hugo Wast, José Ingenieros, Lorenzo Stanchina) y que publicó otros manuscritos en Buenos Aires (Sette, Memórias intimas). En otras palabras: tanto él como Cyro y Caiuby, escritores de menor prestigio, trazaron una estrategia de acceso al mercado, que los periódicos porteños les proporcionaron, quizás como forma de compensar sus dificultades en Brasil.

Ese discreto boom de las traducciones se concentraba en publicaciones periódicas de gran tiraje y amplia circulación entre los lectores argentinos (Prieto, El discurso criollista; Sarlo, El imperio; Rogers, Caras y Caretas). Tanto Paulo Barreto como Julia Lopes de Almeida participaron en esa penetración de la producción brasileña en Argentina (Almeida, El lazo azul; Almeida, La carnada; Barreto, El fin de Arsenio Godard; Barreto, Aventura de hotel). Es notable que los cuentos de Almeida y Barreto fuesen publicados uno o dos años después de sus 
estadías en Buenos Aires. No hay noticias en los diarios consultados de que Almeida haya regalado sus libros en Buenos Aires, pero Barreto lo hizo (En honor de João do Rio 1) y hay indicios de que esa era una práctica común entre la diplomacia cultural informal. Otro posible indicador de la existencia de una tendencia es que en la segunda mitad de la década de 1920 disminuyen las traducciones de cuentos, novelas cortas y poemas, al menos en las publicaciones periódicas mencionadas. Sin embargo, puede haber sido esa difusión de narrativas breves el factor que despertó en Monteiro Lobato el interés por el mercado argentino. El escritor paulista, a partir de 1920, trazó una clara estrategia destinada a entablar contactos principalmente con Benjamin de Garay, con la oferta de intercambiar en la publicación reseñas y artículos de críticas, además de enviar novelas y cuentos para traducir al castellano, llegando a residir en Buenos Aires, en la década de 1940, con el objetivo de fundar una editorial (Gurgel, Monteiro Lobato).

\section{Conclusión}

La imagen de Buenos Aires como una capital moderna, modelo en América, que se ve reflejada en la retórica de los diarios brasileños acerca de los viajes de Paulo Barreto y Julia Lopes de Almeida, significó que los autores que tuvieron la oportunidad de incluirse en el circuito de la diplomacia cultural informal, en la cual la prensa tuvo un papel central, también se granjearon admiración y respeto, lo que se puede observar a través de los agasajos que recibieron en el exterior, como fue divulgado en la prensa de la época (de Buenos Aires y de Río). Además, se nota la penetración del cuento, de la poesía y de la novela corta brasileña, sobre todo a partir del surgimiento en 1918 de las publicaciones semanales de los "novelines" (Sarlo, El imperio 29). Se puede afirmar que durante las tres primeras década del siglo XX, los principales autores brasileños posteriores a 1880 , sin prejuicios de "escuelas" (simbolismo, parnasianismo, realismo, modernismo y regionalismo), se 
hicieron conocidos del público argentino y, justamente entre los viajes de Paulo Barreto y de Julia Lopes de Almeida, Buenos Aires pasó a formar parte del circuito de consagración de dicha literatura, la cual se vinculaba a la prensa periódica, ya se tratara de diarios comerciales o de publicaciones semanales de comunicación masiva.

\section{Bibliografía}

“A Argentina contemporânea”, O País, 22 de junio de 1922: 3-4.

Albuquerque, Joaquim Maria de Medeiros e. "Cuentos", La Novela Para Todos, junio de 1919.

. "El galeote", Plus Ultra, marzo de 1919.

. "Caboche", Atlántida, 02 de marzo de 1922.

Alcalá, May Lorenzo. Vanguardas argentinas: anos 20, ed. Jorge Schwartz. São Paulo: Iluminuras, 1992.

Almeida, Julia Lopes de. Ansia eterna. Río de Janeiro: Garnier, 1903. . "La tuerta”, La Nación, 22 de octubre de 1922, p. 8. . "El lazo azul", La Novela Semanal, 27 de agosto de 1923. . "La carnada", La Novela Semanal, 01 de octubre de 1923, p. 56-62. . "La carnada", La Novela Semanal, 08 de octubre de 1923, p. 57-62 . "La carnada”, La Novela Semanal, 15 de octubre de 1923, p. 59-63. . "La carnada", La Novela Semanal, 29 de octubre de 1923, p. 61-61. . A isca. Río de Janeiro: Leite Ribeiro, 1922.

Alves, Regina Célia dos Santos. "Entre o cristal e a chama: João do Rio e as leituras do urbano". Estudos Linguísticos, 38/ 3 (2009): 395-409.

Ariza, Julia. "Bellezas argentinas y femmes de lettres: representaciones de la mujer en la revista ilustrada Plus Ultra (1916-1930)", Impresiones 
porteñas: imagen y palabra en la historia cultural de Buenos Aires, ed. Laura Malosetti Costa y Marcela Gené. Buenos Aires: Edhasa, 2009. 81106.

Arlt, Roberto. Aguafuertes cariocas: crónicas inéditas desde Río de Janeiro.

Buenos Aires: Adriana Hidalgo, 2013.

Artundo, Patricia. Mário de Andrade e a Argentina: um país e sua produção cultural como espaço de reflexão. São Paulo: EdUSP, 2004.

“Aspectos del desenvolvimiento y la vida actual del Brasil”, La Nación, 11 de octubre de 1922, p. 4.

"Aspectos del desenvolvimiento y la vida actual del Brasil”, La Nación, 11 de octubre de 1922, p. 4.

Assis, Joaquim Maria Machado de, "La echadora de cartas", La Novela Universal, 05 de enero de 1921. . "El diplomático”, La Novela Universal, 05 de enero de 1921. . “La deseada", Plus Ultra, julio de 1922, p. 30-31. . “El enfermero”, Atlántida, 28 de septiembre de 1922.

. "Una absolución”, Atlántida, 28 de junio de 1923.

Azevedo, Aluísio, “En el Marañon”, Fray Mocho, 18 de marzo de 1919. . "La serpiente”, Fray Mocho, 26 de agosto de 1924. . "La ultima partida", Atlántida, 13 de agosto de 1925.

Azevedo, Cyro de, "Dorio”, La Novela Universal, 10 de junio de 1918. . “Alma doliente”, El Cuento Ilustrado, 07 de junio de 1918.

Barreto, Paulo. Vida vertiginosa. Río de Janeiro: Garnier, 1911. . “A imprensa Argentina”, Gazeta de Notícias, 05 de abril de 1915, p. 2. . Sésamo. Río de Janeiro: Francisco Alves, 1917. . "El fin de Arsenio Godard”, Plus Ultra, abril de 1917. . “Aventura de hotel”, Plus Ultra, mayo de 1918.

"Biblioteca del Consejo Nacional de Mujeres", La Nación, 28 de octubre de 1922, p. 4.

Bilac, Olavo, “Soneto", Fray Mocho, 07 de enero de 1919. 
. "La ronda nocturna", Atlántida, 09 de marzo de 1922.

. "Inania verba", Céltiga, 10 de noviembre de 1926.

Bourdieu, Pierre. "O mercado de bens simbólicos". A economía das trocas simbólicas. São Paulo: Perspectiva, 2001. 99-181.

Bravo, Álvaro Fernández. "Redes latinoamericanas en los años cuarenta: la revista Sur y el mundo tropical". Episodios en la formación de redes culturales en América Latina, ed. Claudio Maiz y A. F. Bravo. Buenos Aires: Prometeo, 2009. 113-135.

Bruno, Paula (ed.). Visitas culturales en la Argentina (1898-1936). Buenos Aires: Biblos, 2014.

Caiuby, Amando, “El tísico”, La Novela Semanal, 25 de junio de 1923. . Noites de plantão. San Pablo: Monteiro Lobato e Cia.,1923.

Chartier, Roger. “Textos, impressos, leituras”. A história cultural: entre práticas e representações. Lisboa: Difel, 1990. 121-139.

“Círculo de la Prensa: ayer se efectuó una recepción”, La Nación, 19 de octubre de 1922, p. 2.

"Como nos vê o povo argentino - A cultura brasileira e o seu apreço no continente - Uma entrevista com D. Julia Lopes de Almeida", $O$ Imparcial, 10 de noviembre de 1922, p. 1.

“Conferencia sobre o Brasil em Buenos Aires”, Ilustração Brasileira, 13 de mayo de 1922.

Corbin, Alain. “A relação íntima ou os prazeres da troca”. História da vida privada 4: da Revolução Francesa à Primeira Guerra. São Paulo: Companhia das Letras, 1991, pp. 503-561.

Darío, Rubén, “Diplomáticos poetas: Fontoura Xavier”, La Nación, 30 de abril de 1909, p. 5.

De Luca, Leonora. "Feminismo e iluminismo em Júlia Lopes de Almeida (18621934)". Ciência \& Trópico, vol. 25, n. 2, 1997, pp. 213-236.

Diz, Tania. Alfonsina periodista: ironía y sexualidad en la prensa argentina (1915-1925). Buenos Aires: Libros del Rojas, 2006. 
CATEDRAL TOMADA: Revista literaria latinoamericana / Journal of Latin American Literary Criticism Joao Paulo Coelho de Souza Rodrigues

El Far, Alessandra. A encenação da imortalidade: uma análise da Academia Brasileira de Letras nos primeiros anos da República (1897-1924). São Paulo: FAPESP/FGV, 2000.

“El Sr. Pablo Barreto (Joao do Rio)", El Diario, 18 de abril de 1915, p. 1.

"El Sr. Pablo Barreto", El Diario, 18 de abril de 1915, p. 4.

"Embarcou para esta capital a escritora patrícia D. Julia L. De Almeida", $O$

Imparcial, 03 de noviembre de 1922, p. 9.

"En honor de Pablo Barreto", La Mañana, 20 de abril de 1915, p. 2.

"En honor de Barreto - el banquete de anoche", La Tribuna, 20 de abril de 1915, p.1.

"En honor del Sr. Barreto - la comida de anoche", La Nación, 20 de abril de 1915, p. 2.

"En honor de Joao do Rio", El Diario, 18 de abril de 1915, p. 1.

"Esplendor y miseria del periodismo", El Diario, 21 de abril de 1915, p. 4.

Fanini, Michele Asmar. "Júlia Lopes de Almeida em retrato e prosa: a propósito do diálogo entre as imagens da escritora e sua produção literaria". Cadernos Pagu, 41 (2013): 159-199.

Farias, Juliana Barreto. "João do Rio e os africanos: raça e ciencia nas crônicas da Belle époque carioca". Revista de História, 162 (2010): 243-270.

Fernández, Josefina. "Los límites morales de la nación: una visita al Buenos Aires de 1880-1930 a través de las revistas científicas y culturales de la época". Imágenes de la nación: límites morales, fotografía y celebración, ed. por Biblioteca Nacional. Buenos Aires: Teseo; Biblioteca Nacional, 2012. 13-163.

Gilbert, Sandra M.; Gubar, Susan. The mad woman in the attic: the woman writer in the nineteenth-century literary imagination. New Haven: Yale University Press, 2000.

Guimaraens, Alphonsus de, "El romance de Yslamia", Fray Mocho, 05 de mayo de 1925.

Guimarães, Luís, "Nocturno", Atlántida, 09 de septiembre de 1920. 
Jobim, José Luís. Trocas e transferencias culturais: escritores e intelectuais nas Américas. Niterói: EdUU, 2008.

"La alta oratoria de anoche", Crítica, 20 de abril de 1915, p. 1.

Lima Barreto, Afonso Henriques de. Recordações do escrivão Isaías Caminha. Lisboa: A. M. Teixeira, 1909.

Lisboa, Rosalina Coelho, "Sonetos", Nosotros, septiembre de 1922, pp. 12-13.

Lobato, José Bento Monteiro, "Mi cuento de Maupassant”, Plus Ultra, noviembre de 1920.

. "El drama de la helada", Plus Ultra, septiembre de 1922.

. "Alma negra”, La Novela Semanal, 16 de mayo de 1923.

. "El rapto", Atlántida, 23 de octubre de 1923.

Mariano, Antonio Olegário, "La hilandera”, Plus Ultra, mayo de 1919.

"Missão auspiciosa", O País, 04 de octubre de 1922, p. 3.

Mérou, Martín García. El Brasil intelectual: impresiones y notas literarias.

Buenos Aires: Félix Lajouane, 1900.

Neto, Henrique Maximiano Coelho, "Segundas nupcias", La Novela Semanal, 01 de septiembre de 1919.

. "El talismán de Arizuma", Plus Ultra, noviembre de 1920.

. "Las palomas", Atlántida, 24 de febrero de 1921.

. "El orfebre", Atlántida, 20 de abril de 1922.

. "Las tres gotas", Fray Mocho, 05 de enero de 1926.

“O Brasil no estrangeiro", O País, 03 de octubre de 1922, p. 1.

"O Brasil no estrangeiro", O País, 19 de octubre de 1922, p. 1.

"O Brasil no estrangeiro", O País, 05 de noviembre de 1922, p. 1.

"O Brasil no estrangeiro: missão intelectual ao Prata", O País, 29 de octubre de 1922, p. 1.

O'Donnell, Julia. De olho na rua: a cidade de João do Rio. Rio de Janeiro: Zahar, 2008.

"Pablo Barreto - su llegada", La Nación, 18 de abril de 1915, p. 1.

"Pablo Barreto", La Mañana, 19 de abril 1915, p. 1. 
Pesavento, Sandra Jatahy. O imaginário das cidades: visões literárias do urbano, Paris, Rio de Janeiro, Porto Alegre. Porto Alegre: Editora da UFRGS, 2002.

“Poetas brasileños modernos”, Atlántida, 17 de agosto de 1922.

“Poetas brasileños modernos", Atlántida, 28 de septiembre de 1922.

Ribeiro, Maria Paula Gurgel. Monteiro Lobato e a Argentina: mediações culturais. Tesis de Doctorado en Letras, Universidad de San Pablo, 2008.

Rio, João do. O momento literário. Río de Janeiro: Fundação Biblioteca Nacional, 1994.

Rivera, Jorge B. El escritor y la industria cultural. Buenos Aires: Atuel, 1998.

Rocca, Pablo. "Machado de Assis, escritor do Rio da Prata: duas hipóteses contraditórias ”. Cadernos de Letras da UFF, 38 (2009): 35-49.

Rodrigues, João Paulo Coelho de Souza. “A geração boêmia: vida literária de 1880 a 1920 em romances, memórias e biografias". A história contada: capítulos de história social da literatura no Brasil, ed. Sidney Chalhoub y Leonardo Affonso de M. Pereira, Río de Janeiro: Civilização Brasileira, 1998. 233-263. . "Da revolução à regeneração: crônicas de Machado de Assis e Olavo Bilac sobre a Argentina". Antíteses, vol. 6, n. 11, 2013, pp. 127-148. . "Embaixadas originais: diplomacia, jornalismo e as relações ArgentinaBrasil (1888-1935)". Topoi, vol. 18, n. 36, 2017, pp. 537-562.

Rogers, Geraldine. Caras y Caretas: cultura, política y espectáculo en los inicios del siglo XX argentino. La Plata: EdULP, 2008.

Sarlo, Beatriz. El imperio de los sentimientos: narraciones de circulación periódica en Argentina (1917-1927). Buenos Aires: Siglo XXI, 2011.

Sette, Mario, "Rastro de sangre”, La Novela Semanal, 17 de julio de 1922. . João Ignacio. Porto: Livraria Chardron de Lello e Irmão, 1928. . Memórias íntimas: caminhos de um coração. Recife: Fundação de Cultura Cidade do Recife, 1980. 
Sirinelli, Jean-François. "Os intelectuais". Por uma história política, ed. René Rémond, Rio de Janeiro: Editora FGV, 2003. 231-269.

"Sonetos brasileños", Fray Mocho, 03 de enero de 1918.

Sorá, Gustavo. Traducir el Brasil: una antropología de la circulación internacional de ideas. Buenos Aires: Libros del Zorzal, 2003.

Souza, Claudio de, “La conversión”, La Novela Semanal, 15 de julio de 1918.

Süssekind, Flora. Cinematógrafo de letras: literatura, técnica e modernização no Brasil. São Paulo: Companhia das Letras, 1987.

Ubatuba, Ezequiel, "Yuacá: leyenda brasileña”, Plus Ultra, mayo de 1924.

Veríssimo, José. Homens e coisas estrangeiras (1899-1908). Río de Janeiro: Topbooks, 2003.

"Vida intelectual", La Razón, 10 de octubre de 1922, p. 4.

"Vida intelectual", La Razón, 28 de octubre de 1922, p. 4.

"Vida social", El Diario, 20 de abril de 1915, p. 8. 